\title{
Trouble still Brewing over Law of the Sea
}

BRITISH proposals affecting the law of the sea have been heavily criticized by the Parliamentary Group for World Government. The all party group, which embraces both houses of Parliament, declared last week that the proposals would "effectively remove from mankind the richest part of its heritage, endanger freedom of scientific research and increase the likelihood of international conflict".

The proposals that have aroused the group's fury provide for a grid systemof the type used to regulate oil prospecting in the North Sea and elsewhere-which will divide up the area of the world's ocean into administrative areas for exploitation.

The proposal has been about for some time, but the group's action appears to be prompted by the start, on July 2 , of the final preparatory meeting for the United Nations' Law of the Sea Conference planned for Santiago next year.

Under the British proposal-which is by no means guaranteed approval by the Santiago conference - the world's oceans would be divided up into large rectangles which any nation could license from the International Sea Bed Authority that is to be set up by the Santiago conference. Each nation could then exploit its part of the oceans. The proposal also provides that only a small percentage of the oceans would be licensed initially-perhaps five or ten per cent-in order that the developed nations do not gain further economic advantages over the under developed.

To further ensure what is described as an "equitable distribution", the licences would be granted on a quota basis, which takes into account population.

Developing countries would also be able to sub-licence companies in developed countries to actually exploit sea bed resources for them, benefiting both from the immediate return on the work and from the experience of the technology.

The parliamentary group ridicules this scheme describing it as a twentieth century enclosure act and predicting that it will cause international conflict. Unfortunately the group has nothing to put in place of the British proposal.

There is, however, an alternative, and currently it seems to have more explicit support than the British proposal. Its advocates include many of the developing countries and its aim is to create an International Sea Bed Authority that will actually exploit the oceans itself, distributing the profits after administration costs.

Objections to the scheme-largely voiced by the developed countries-are that the cost of setting up such a commercial organization to exploit the minerals and hydrocarbons beneath the seafloor would be astronomical. Sums larger than the entire budget of the United Nations would be needed, Britain has claimed.

Defining the constitution of such an authority might well prove an insuperable task, as it would have not only to to be strong commercially, but would have to be able to resist political pressure-for example from copper producing countries who might try and restrict the mining of manganese nodules. Equally, past experience with international organizations does not suggest that a commercially orientated one would be any more successful than its diplomatic predecessors.

The parliamentary group also warns of the dangers presented to scientific research by other proposals before the conference. Extension of "patrimonial seas" to 200 miles from land-a proposal that may well be approved in one form or another at Santiago-could hamper scientific research, the group claims, and in doing so it is reflecting well-founded

\section{NATURAL RESERVES}

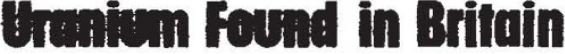

Several thousand tons of uranium oxide ore have been found in Britain. The discovery of the ore was in fact made some years ago at the start of the Institute of Geological Science's five year search for uranium which it has been conducting on behalf of the United Kingdom Atomic Energy Authority. The $\mathbf{f 0 . 2 5}$ million programme revealed deposits of the ore in northern Scotland, Cornwall and Devon, but full announcement of the discovery was not made until last week. A preliminary announcement that some ore was present near Ousdale burn in Caithness was made in $1970^{1}$.

IGS is unwilling as yet to say how much ore has been found, or to say precisely where it is, although, apparently, it is not located in national parks. Dr S. H. U. Bowie, chief geochemist at IGS, said this week that while the ore is not of grade one standard, it still represents an "important strategic reserve".

The current price of recovered uranium oxide is just under $\$ 10$ a pound. The price will have to rise to between $\$ 10$ and $\$ 15$ a pound before fears that the scientific community has been expressing for some time (see Nature, 239, 421 ; 1972). A large block of the developing countries, notably the South Americans and Africans, are claiming that scientific research is merely a mask for commercial exploitation of the seabed (in the words of a Peruvian delegate "knowledge is power and must therefore be controlled"). What the developing countries are proposing is that scientific research should be carefully regulated by the International Seabed Authority, which would not only grant permission for scientific research on the high seas, but which would also have access to all results before they were published.

Currently this proposal is being strongly opposed by the developed countries---USSR included. Firm declarations have been made that scientific research must be kept free. It remains to be seen how much the attitude of the Africans and South Americans is simply a negotiating position, but there remains a danger that scientific research could suffer if the interests of defence and economics alone rule in Santiago next year.

it becomes economic to mine the newly discovered deposits. At present there is a world surplus of uranium but by the mid-1980s it is expected that the price - which has remained stable for some time--will begin to rise. At that point the British deposits might prove worth mining.

Although they are small in comparison with the estimated world deposits (100 million million metric tons, 2.5 million million of which are within a mile of the surface), they might, if they proved to be in the order of 8,000 tons, provide enough energy to meet the equivalent of the whole of the United Kingdom's current electricity demand for about 50 years. Whether in fact the find will be good for that long will not be known until the IGS provides more details, probably later this year.

The five year programme, which ended in March, involved searching five areas of Britain - northern Scotland, the southern uplands of Scotland, the Midlands, Central Wales and south western England. Before the search began the likeliest sites were considered to be Devon and Cornwall and northern Scotland, including the Caithness and Orkney areas.

${ }^{1}$ Institution of Mining and Metallurgy Transactions B, 79, 180; 1970. 